\title{
ARVUTI SUHTLUSES
}

\section{Mare Koit}

Ülevaade. Artiklis käsitletakse probleeme, mis tuleb lahendada selleks, et arvutiga saaks suhelda loomulikus keeles, sh eesti keeles. Tuuakse näiteid arvutitega suhtlemise kohta, alustades A. M. Turingi mõtlemisvõimelise arvuti ideest 1950. a kuni kaasaegsete loomulike liidestega dialoogsüsteemide ja robotiteni. Tutvustatakse akadeemilist ja insenerlikku lähenemist dialoogsüsteemide loomisele ning kahte paradigmat, mida dialoogi automaattöötluses on rakendatud - ratsionalismi ja empirismi. Antakse ülevaade töödest, mida on tehtud eesti keeles suhtleva dialoogsüsteemi loomise eesmärgil, sh Tartu Ülikooli eesti dialoogikorpusest ja olemasolevast eesti keele automaattöötluse tarkvarast. Lõpuks vahendatakse tuntud teadlaste tulevikuvisioone arvuti kui suhtluspartneri kohta."

Võtmesõnad: Turingi test, arvutikõne hüpotees, dialoogsüsteem, robot, dialoogikorpus, eesti keel

\section{Sissejuhatus}

Suhtlus arvutiga on intrigeeriv teema. Pole veel sugugi igapäevane, et meie vestluskaaslaseks on robot-tehisinimene või et näiteks helistades infotelefonile kuuleme vastuseks sünteeshäält, mis viisakalt ja kannatlikult vastab ka meie kõige tüütumatele küsimustele. Ometi oli 2006. a aprillikuus võimalik Tallinnaski kohata robotit: rahvusvahelise auto-ja tehnikanäituse Motorex Tallinn külastajad said tutvuda Jaapani firma Honda robotiga Asimo (joonis 1). 1,2 m pikkune tehismehike on täis kõige kaasaegsemat tehnoloogiat ning ta on oodatud külaline kõikvõimalikel suurematel tehnikasündmustel üle kogu maailma. Asimo tunneb ära oma vestluskaaslased, kõnnib, ronib trepil ja kõneleb. Asimo keelelised võimed on siiski veel napid: ta mõistab lihtsaid jaapani- või ingliskeelseid käsklusi ja suudab neile vastata.

Nimetagem veel kahte tähelepanuväärset robotit - Aibo ${ }^{1}$ ja Furby $^{2}$. Aibo on robotkoer, mida toodab Jaapani firma Sony alates 1999. a. Ta liigub, "näeb” keskkonda kaamerate abil, mõistab suulisi käsklusi, õpib, kasutades väliseid stiimuleid

* Artikli valmimist on osaliselt toetanud ETF-i grant nr 5685. 


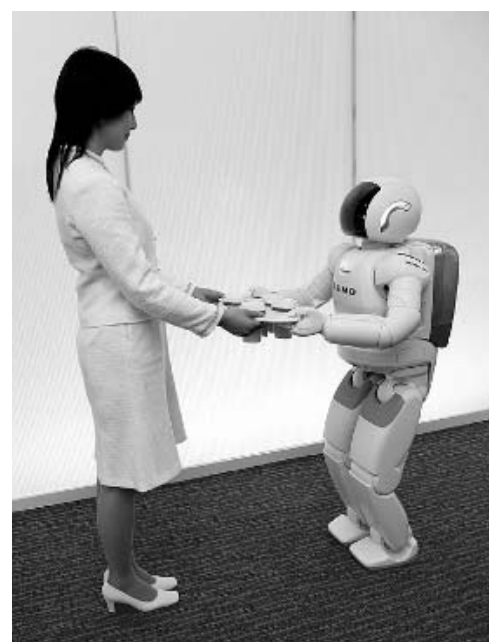

Joonis 1. Robot Asimo kandikut ulatamas ${ }^{3}$

keskkonnast, omanikult või teistelt Aibodelt. Furby on robotloomake, mida valmistab alates 1998. a Tiger Electronics. 2005. a lisati robotile kõnetuvastus. Furby suudab tuvastada kümneid fraase ja hääldada sadu sõnu.

Kõigi nende robotite tegevust juhib sisseehitatud arvuti.

Maailmas kasutatakse lisaks robotitele tuhandeid kõnedialoogsüsteeme, mis suhtlevad inimestega mitmes erinevas keeles, võttes vastu miljoneid telefonikõnesid päevas (Minker jt 2005). Pakutavate teenuste skaala on lai: infotelefon, hädaabi, lennureisi reserveerimine, postisaadetiste jälgimine, telefonikõne suunamine nime järgi, kinnisvarainfo jne.

Kas arvutiga peab saama suhelda inimkeeles? Sellele on nii poolt- kui vastuargumente. Põhiliseks pooltargumendiks on asjaolu, et inimesed ei pea siis ära õppima uut keelt (programmeerimiskeelt või andmebaasi päringukeelt), vaid saavad kasutada loomulikku keelt, mida nad niikuinii juba valdavad. Igas loomulikus keeles on vahendid soovide ja kavatsuste väljendamiseks, objektidele viitamiseks ja nende kirjeldamiseks, konteksti arvestamiseks (anafoor, ellips). Kõne kasutamine jätab muude ülesannete jaoks vabaks käed ja silmad. Põhiliseks vastuargumendiks on tehnoloogilised piirangud: kuna kõnetuvastus ja keele automaatne mõistmine pole veel saavutanud inimese taset, siis on raske defineerida arvuti jaoks adekvaatset sisendkeelt, et vältida mitmesust ja vigu. Arvuti keeleline ja arutlusvõime pole inimesele arusaadavad.

\section{Elizast Alice'ini: kas arvuti mõistab keelt?}

Esimene tuntuks saanud programm, mis suhtles kasutajaga inglise keeles, oli 1966. a valminud ELIZA (Weizenbaum 1966). Dialoog (1) on näide vestlusest ELIZA-ga. ${ }^{4}$

(1) Dialoog ELIZAga (Weizenbaum 1966). K - kasutaja, A - arvuti, s.o ELIZA 
K: Men are all alike.

A: In what way?

K: They're always bugging us about something or other.

A: Can you think of a specific example?

K: Well, my boyfriend made me come here.

A: Your boyfriend made you come here.

$\mathrm{K}$ : He says I'm depressed much of the time.

A: I am sorry to hear you are depressed.

K: It's true. I am unhappy.

A: Do you think coming here will help you not to be unhappy?

$\mathrm{K}$ : I need some help, that much seems certain.

A: What would it mean to you if you got some help?

$\mathrm{K}$ : Perhaps I could learn to get along with my mother.

A: Tell me more about your family.

Arvuti vestleb kasutajaga näiliselt arukalt, kuid see on saavutatud väga lihtsate vahenditega: ELIZA kasutab võtmesõnade andmebaasi (vt tabel 1). Iga võtmesõna jaoks on antud 1. nn järk (täisarv), 2. šabloon, millega võrrelda sisendit, 3. väljundi (vastuslause) spetsifikatsioon. Analüüsides kasutaja lauset, leiab ELIZA selles võtmesõna, mille šabloon sobib lausega (nt alike). Kui võtmesõnu on rohkem kui üks (nt esimeses lauses are ja alike), siis valib ta neist sellise, mille järk on suurim (antud juhul alike), ning vastuslausena kasutab võtmesõnaga seotud väljundi spetsifikatsiooni (antud näites In what way?). Kui analüüsitavas lauses ei leidu ühtki võtmesõna, siis annab ELIZA “ohutu” vastuse, nt Tell me more... (nagu joonisel 2 toodud näite viimases reas) või Go on.

Tabel 1. Väljavõte ELIZA andmebaasist (Weizenbaum 1966). X,Y - suvalised tekstid

\begin{tabular}{|c|c|c|l|}
\hline Võtmesõna & Järk & Šabloon & \multicolumn{1}{c|}{ Väljundi spetsifikatsioon } \\
\hline alike & 10 & $X$ & $\begin{array}{l}\text { In what way? } \\
\text { What resemblance do you see? }\end{array}$ \\
\hline are & 3 & $\begin{array}{c}\text { Xare you } Y \\
\text { Xare } Y\end{array}$ & $\begin{array}{l}\text { Would you prefer it if I weren't Y? } \\
\text { What if they were not Y? }\end{array}$ \\
\hline always & 5 & $X$ & $\begin{array}{l}\text { Can you think of a specific example? } \\
\text { When? } \\
\text { Really, always? }\end{array}$ \\
\hline what & 2 & $X$ & $\begin{array}{l}\text { Why do you ask? } \\
\text { Does that interest you? }\end{array}$ \\
\hline
\end{tabular}

ELIZA eeskujul on koostatud ka mitmeid eesti keeles suhtlevaid programme, nt 1999. a tollase informaatikaüliõpilase Mart Tudre programm Liisbet, mis valmis kursuse "Sissejuhatus arvutuslingvistikasse“ raames. Dialoogis (2) on toodud katke Liisbetiga.

(2) Liisbet - eestikeelne Eliza (Tudre 1999). K - kasutaja, A - arvuti, s.o Liisbet

A: Mina olen Sinu algaja psühhoanalüütik-abimees Liisbet.

Räägi palun mulle oma probleemidest.

$\mathrm{K}$ : Mul on raske suhelda inimestega. 
A: Ah nii.

K: Ma ei leia nendega kontakti.

A: Oled Sa kindel?

K: Muidugi, selles ei maksa kahelda.

A: Miks mitte?

K: Sellepärast, et kõik ütlevad, et ma olen halb suhtleja.

A: Kas Sulle meeldib olla halb suhtleja?

Kumbki, ei ELIZA ega Liisbet, ei mõista keelt, vaid reageerivad vestluskaaslase lausetest leitud märksõnadele ning on seega suutelised vestluses etendama üksnes suhteliselt passiivset rolli. Tõsi, mõnes piiratud rakenduses, kus inimesele on esmatähtis, et teda kuulataks ja aeg-ajalt kuuldel olekust märku antaks, võib seegi piisavaks osutuda.

Kuidas ära tunda, et arvuti saab vestluskaaslasest ka tegelikult aru? Inglise matemaatik A. M. Turing pakkus selleks nn jäljendamismängu, mida hiljem on hakatud nimetama Turingi testiks. Mäng seisneb järgnevas (Turing 1950, 2005). Eksperimentaatori eest varjatult paigutatakse eraldi ruumidesse inimene ja testitav arvuti ning suhtlus toimub loomulikus keeles nt läbi arvutivõrgu. Eksperimentaator esitab küsimusi, kusjuures ta ei tea, kas vastajaks on inimene või arvuti. Kui eksperimentaator ei suuda kindlaks teha, et üks vastajatest on arvuti, siis on arvuti testi läbinud ja võib öelda, et ta on mõtlemisvõimeline. Turing toob ka näite dialoogist, millega arvuti peaks toime tulema (3).

(3) Näide A. M. Turingi artiklist (Turing 2005). K - küsija, A - arvuti

K: Kas teie soneti esimesse ritta - "Kas suvepäeva sarnaseks sind kiita" ei sobiks sama hästi või pareminigi "kevadepäeva"?

A: Rütm läheks sassi.

K: Aga "talvepäeva"? See sobiks rütmiga.

A: Jah, aga talvepäeva moodi ei taha ju keegi olla.

$\mathrm{K}$ : Kas hr Pickwick ei meenuta mitte jõule?

A: Mõnes mõttes küll.

K: Aga jõulud on ju talvel ja vaevalt hr Pickwick sellist võrdlust pahaks paneks.

A: Nalja teete. “Talvepäeva” all peetakse silmas ikka mõnda tüüpilist, mitte näiteks jõululaupäeva moodi erilist talvepäeva.

Ajal kui A. M. Turing oma artikli kirjutas, oli arvutite tootmine alles algusjärgus ning esimesed arvutid üsna tagasihoidlike võimetega. Nüüdseks, üle viiekümne aasta hiljem, ei ole ikka veel suudetud luua arvutit, mis tuleks toime Turingi testiga.

(4) Vestlus Alice'iga

PROGRAM[02:19:16] My name is ALICE.

JUDGE05[02:19:37] Good morning Alice. Why have you entered the Loebner Prize?

PROGRAM[02:19:37] Hello and how are you this morning? The Loebner Prize is an annual Turing Test sponsored by New York philanthropist Hugh Loebner. Dr. Wallace and ALICE won it in 2000. The ALICE program was ranked "most human computer" by the panel of judges.

JUDGE05[02:20:14] So you are here today to defend your title? 
PROGRAM[02:20:14] Interesting deduction. Do you mind if I tell other people you say I am here today to defend my title.

JUDGE05[02:20:25] Not at all

PROGRAM[02:20:25] Next question?

JUDGE05[02:21:00] What will you spend the prize money on if you win? PROGRAM[02:21:00] I don't have any plans yet.

1990. a pani ameerika insener dr Hugh Loebner välja kuldmedali ja 100 ooo dollari suuruse auhinna arvutiprogrammile, mis esimesena läbib Turingi testi, ja algatas sellega iga-aastase võistluse. ${ }^{5}$ Kolm korda (2000, 2001 ja 2004) on võitjaks tulnud ning pronksmedali ja 2000-dollarilise lohutusauhinna pälvinud programm Alice ${ }^{6}$ (autor Richard Wallace), mida mõnigi kohtunik on pidanud inimeseks. Näites (4) on toodud katkend 2001. a võistluste protokollist ${ }^{5}$. Kahel viimasel aastal (2005 ja 2006) võitis programm Jabberwacky ${ }^{7}$ (autor Rollo Carpenter), kus rakendatakse masinõpet.

Programmid, mille peaülesanne on inimesega loomulikus keeles suhelda (nn juturobotid), pakuvad küll meelelahutust, aga samas ka innustavad uurijaid oma programme järjest täiustama ja uusi lahendusi välja mõtlema. Lihtsast võtmesõnapõhisest keeletöötlusest siin muidugi ei piisa.

\section{Praktilised dialoogsüsteemid}

\subsection{Esimesed küsimus-vastussüsteemid}

Küsimus-vastussüsteemide loomine algas 1960. aastate lõpul. Peagi eraldusid kaks suunda: akadeemiline ja insenerlik.

Akadeemilised süsteemid põhinesid sügavatel teooriatel, järgisid tehisintellekti traditsiooni, modelleerides arutlust ja keele mõistmist maailmateadmuse põhjal. Üheks tähelepanuväärseks selle suuna esindajaks oli süsteem Shrdlu ${ }^{8}$ (autor Terry Winograd, 1972) - roboti käe mudel arvuti ekraanil nn kuubikute maailmas, mis demonstreeris kasutaja ingliskeelsetest käsklustest arusaamist, vastates neile inglise keeles ja ühtlasi sooritades nõutud tegevusi (vt dialoog 5).

(5) Dialoog Shrdluga

Inimene: find a block which is taller than the one you are holding and put it in the box

Shrdlu: OK.

Inimene: what does the box contain?

Shrdlu: The blue pyramid and the blue block.

Inimene: what is the pyramid supported by?

Shrdlu: The box.

Inimene: how many blocks are not in the box?

Shrdlu: Four of them.

Insenerisüsteemides seevastu tähtsustati täitmisomadusi. Üks tuntumaid süsteeme - PARRY9 (autor K. M. Colby, 1971) - jäljendas paranoikut. Programm kasutas ligi 6000 mustrit, millega võrdles sisendit, et sellele õigesti reageerida. See võimaldas tal pidada tõepäraseid dialooge, tehes aeg-ajalt kõrvalekaldeid initsiatiivi

${ }^{5}$ http://www.loebner.net/Prizef/loebner-prize.html (8.09.2006) 
haaramiseks, mida võis hea tahtmise juures panna ka paranoilise käitumise süüks. Näites (6) püüab Parry viia juttu kihlvedudele - teemale, mida ta hästi valdab.

\subsection{Ratsionalism ja empirism}

Akadeemiline ja insenerlik suund esindasid dialoogsüsteemide loomisel kumbki kahte erinevat paradigmat - vastavalt reeglipõhist (e ratsionaalset) ja andmepõhist (e empiirilist). Ratsionalism oli kuni 1990. aastate alguseni ainuvaldav. Andmepõhine dialoogitöötlus oli selle ajani raskendatud, sest erinevalt tekstikorpustest (mille kasutuselevõtt tekitas pöörde masintõlkes juba 1980. aastate lõpul, vt Brown jt 1990), hakati dialoogikorpusi looma alles 1990. a. Tõsi, kõnetuvastusel ja -sünteesil oli juba varem rakendatud statistilisi meetodeid, kuid kõnetöötlust oli käsitletud dialoogist eraldi, olgugi et kõne fenomenid (pausid, rõhud, kontuurid jms) annavad edasi tähendusi ja aitaksid dialoogis kaasvestlejast aru saada. 1990. aastatel jõudis empirism ka akadeemilistesse dialoogsüsteemidesse.

(6) Dialoog Parryga

Inimene: Good afternoon. My name is Doctor Jones.

PARRY: Pleased to meet you.

Inimene: How are you?

PARRY: All right I guess.

/---/

Inimene: I thought you might have some problems.

PARRY: I've been upset lately.

Inimene: By what?

PARRY: People get on my nerves sometimes.

Inimene: Tell me more.

PARRY: Do you know anything about bookies?

Inimene: No. What about bookies?

PARRY: A bookie didn't pay me off once.

Inimene: When did this happen?

PARRY: A couple of months ago.

Üks parimaid sel ajal loodud süsteeme oli TRAINS ${ }^{10}$ (autor David Traum Rochesteri ülikoolist, 1994), kus võeti kasutusele dialoogikorpus, aga samas säilitati ka loogiline arutlus. TRAINS pidas kasutajaga inglise keeles dialoogi kooperatiivse ülesande lahendamiseks - kaubavedude organiseerimine Ameerika Ühendriikide idarannikul, kasutades abivahendina ka kaarti. Süsteemis olid realiseeritud kõnetuvastus ja -süntees. Näites (7) on esitatud katkend dialoogist süsteemiga TRAINS, mis demonstreerib, et süsteem mõistab kasutajat ja oskab talle ülesande lahendamisel nõu anda.

(7) Dialoog süsteemiga TRAINS (kõne on transkribeeritud)

utt1 : s(ystem): hello < sil> can I help you

utt2 : u(ser): yeah I want t- I want to determine the maximum number of boxcars of oranges $<$ sil $>$ by seven a.m. $<$ sil $>$ tomorrow morning utt3 : so <brth $>$ hm $<$ sil $>$

${ }^{10} \mathrm{http}: / /$ www.cs.rochester.edu/research/trains/ (8.09.2006) 
so I guess all the boxcars will have to go through oran- < sil $>$ through Corning because that's where the orange juice $<$ brth $>$ orange factory is

utt4 : so from Corning to Bath how far is that

utt5 : s: two hours

utt6 : u: and it's gonna take us also an hour to load < sil > boxcars right

utt7 : s: right ++

utt8 : u: + okay + so $<$ sil $>$ hm so $<$ sil $>$ every trip will take at least $<$ sil $>$ three

hours $<$ sil $>$ then

utt9 : um

utt10 : s: right we can unload any amount of cargo onto a train in one hour

utt11 : so we can $+<$ sil $>$ so a maximum of three + boxcars in an hour

\subsection{Empirismi võidukäik}

Praegu domineerib dialoogitöötluses, nagu loomuliku keele automaattöötluses üldse, empirism. Seda toetab arvestatav hulk märgendatud dialoogikorpusi, millest tuntumad on Switchboard, Verbmobil, BNC (McTear 2004). See võimaldab kasutada lausungis dialoogiakti tuvastamisel masinõpet ja dialoogi juhtimisel dialoogiaktide järjendite statistikat.

Värsketest uurimustest on tähelepanuväärne lähenemine, mis käsitleb dialoogi kui osaliselt vaadeldavat Markovi otsustusprotsessi (Partially Observable Markov Decision Process) (Williams, Young 2006). Ühe konkreetse dialoogioleku asemel uuritakse kõikvõimalike olekute tõenäosusjaotust, nn arvamusolekut (ingl belief state), mis dialoogi käigus võib muutuda. Selliseid otsustusprotsesse kasutatakse tegevuste valikuks olukorras, kus maailm (olekute ruum) ei ole otseselt vaadeldav. Kui tuua hästi arusaadavaid võrdlusi, siis nt male on otseselt vaadeldav mäng: kõigi malendite positsioon alati nähtav. Seevastu pokker on osaliselt vaadeldav: teades oma kaarte, vastaste pakkumisi ja laual olevaid kaarte, võib ainult oletada, millised kaardid on vastastel. Sarnasel viisil on ka dialoog osaliselt vaadeldav protsess.

Praegustes dialoogsüsteemides kasutatakse nelja lähenemist.

1. Loogikapõhised süsteemid, kus rakendatakse arutlust (täitmisomadustele ei pöörata erilist tähelepanu).

2. Kõnetehnoloogiat, masinõpet ja lihtsaid vahestruktuure kasutavad süsteemid.

3. Lihtsad olekuautomaadid inimese ja arvuti vaheliste suuliste dialoogide kirjeldamise keeles VoiceXML ${ }^{11}$. Selles keeles esitatud dokumentide interpreteerimiseks on loodud spetsiaalsed häälebrauserid. Süsteemi ülesehitamiseks ühendatakse brauserite andmepangad avaliku telefonivõrguga. Sellisel viisil on loodud palju juturoboteid ja mitmesuguseid kommertssüsteeme.

4. Hübriidsüsteemid, mis ühendavad reeglid ja masinõppe.

${ }^{11}$ http://www.voicexml.org/ (8.09.2006) 


\subsection{Kõnedialoogsüsteemide näiteid}

Maailmas on dialoogsüsteemide arendamine kestnud juba ligi neli aastakümmet. Esimesed lihtsad süsteemid, mis suhtlevad kasutajaga kõne abil, jõudsid kommertsrakendusteni siiski alles 15 aastat tagasi. Need on mitmesugused teadetesüsteemid (annavad liiklusinfot, pangainfot vms), ärikokkulepete sõlmimise (pangalaenu saamise, autokindlustuse, ostuabi jms) süsteemid, probleemilahendusel (nt arvutirikke tuvastusel) abistavad süsteemid.

Alljärgnevalt on ülevaade mõnede tuntud firmade dialoogsüsteemidest, millega saab suhelda kõne abil.

- Nuance (Ameerika Ühendriigid) võimaldab kasutada häälvalimisega telefoni, e-posti ettelugemist, kindlustust, pangateenust, annab reisiinfot jms. $^{12}$

- $\quad$ AT\&T Labs (American Telephone and Telegraph, Ameerika Ühendriigid) pakub kellaja teatamise, krediidiinfo jms süsteeme. ${ }^{13}$

- Philips (Holland) toodab dikteerimissüsteeme, telefoniteenuste süsteeme. ${ }^{14}$

- Rootsi firma Telia ja Soome firma Nokia rakendavad mõlemad oma firmas telefonikõne suunamist töötaja nime järgi; Telia säästab sellega väidetavalt 40 miljonit Rootsi krooni aastas.

- Loquendo (Itaalia) on välja töötanud rongiinfosüsteemi,,$^{15}$ mille andmebaasis on 3000 linna/jaama Itaalia raudteel. Süsteem saab 2 miljonit telefonikõnet kuus.

Dialoogsüsteemide arendamisega tegeldakse paljudes ülikoolides ja uurimisinstituutides.

- Massachusettsi Tehnoloogiainstituudis on loodud mitmeid dialoogsüsteeme, ${ }^{16}$ mis annavad lennuinfot koos piletihindadega, lennukite saabumisja väljumisaegadega, liiklusinfot ja restoraniinfot Bostoni piirkonnas, ilmateateid (enam kui 500 linna kohta üle kogu maailma).

- Carnegie Melloni ülikoolis on loodud kõnedialoogsüsteem CMU Communicator, ${ }^{17} \mathrm{mis}$ aitab planeerida reisi (lennuinfo, piletite, hotelli reserveerimine, autorent).

- Soome ülikoolide ning mõnede Soome ja Jaapani firmade koostöös on lõpule jõudnud projekt Interact ${ }^{18}$ dialoogsüsteemi loomiseks, mis võimaldab suunata telefonikõnesid, reserveerida pileteid, saada infot Helsingi bussisõiduplaanide kohta, interaktiivset abi probleemilahendusel.

- Rochesteri ülikoolis on loodud dialoogsüsteemi TRAINS edasiarendus TRIPS $^{19}$ (The Rochester Interactive Planning System), kus rakendusstsenaariumiks on inimeste päästmine katastroofipiirkonnast, seejuures on aeg ja transpordivahendite arv piiratud. Kasutatakse ka teede kaarti.

- Saksamaa Tehisintellekti Uurimisinstituudis on professor Wolfgang Wahlsteri juhtimisel läbi viidud mitmeid suuri projekte inimesega loomulikus keeles suhtlevate dialoogsüsteemide loomiseks.

\footnotetext{
${ }^{12} \mathrm{http} / / /$ www.nuance.com/speech/ (8.09.2006)

${ }^{13}$ http://www.att.com/attlabs/ (8.09.2006)

${ }^{14}$ http://www.philips.com/ (8.09.2006)

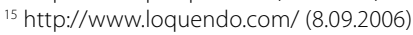

${ }^{16} \mathrm{http}: / /$ www.sls.lcs.mit.edu/applications (8.09.2006)

${ }^{17}$ http://www.speech.cs.cmu.edu/Communicator/ (8.09.2006)

${ }^{18}$ http://www.mlab.uiah.fi/interact/ (8.09.2006)

${ }^{19} \mathrm{http}: / /$ www.cs.rochester.edu/research/trips (8.09.2006)
} 
- Verbmobil ${ }^{20}$ (1993-2000) on kohtumiste kokkuleppimise süsteem, mis hõlmab ka reisiplaneerimise ja kõike sellega seonduva (nt hotelli reserveerimine) ning ühtlasi võimaldab automaatselt tõlkida kõnet ühest keelest teise (valida on kolme keele vahel: saksa, inglise ja jaapani keel).

- SmartKom ${ }^{21}$ (1999-2003) on mitmefunktsiooniline dialoogsüsteem, millel on kolm põhilist rakendusstsenaariumi:

- $\quad$ SmartKom-Public - multimodaalne telefoniautomaat (kaasatud on nii kõne kui ka žestid ja miimika),

- $\quad$ SmartKom Mobile - Interneti-teenused mobiiltelefoni teel,

- SmartKom-Home / Office - arvuti hääljuhtimine mitmesugusteks rakendusteks, sh dokumentide dikteerimine, infootsing Internetist jms.

- VirtualHuman ${ }^{22}$ (2002-2006). Eesmärk on arendada virtuaalseid (emotsionaalseid ja fotorealistlikke) karaktereid. Põhitähelepanu pööratakse personaalsete dialoogipartnerite loomisele, mis tegutsevad reaalajas ja autonoomselt. Ühe võimaliku rakendusstsenaariumina nähakse e-õpet.

Tuleb rõhutada, et praegu on aktuaalseks uurimisprobleemiks multimodaalne suhtlus arvutiga, mis lisaks loomulikule keelele (eeskätt suulisele keelele) hõlmab ka žeste, miimikat, sh emotsioonide edasiandmist ja tõlgendamist jms.

Üks suurejoonelisemaid projekte on Cyc (sõnast encyclopedy), mida alustati Ameerika Ühendriikides juba 1984. a. Projekti eesmärk on luua väga mahukas mõisteid, fakte ja reegleid koondav teadmusbaas, mille abil tehisintellektisüsteem suudaks arutleda, õppida ja inimesega loomulikus keeles suhelda. Juulis 2006 valminud versioon sisaldab 47000 mõistet ja 306000 fakti. ${ }^{23}$

\section{Eesti keeles suhtlev arvuti}

Tartu Ülikoolis tegutseva keeleteadlaste ja informaatikute rühma eesmärk on modelleerida arvutil loomulikku dialoogi, s.t sellist dialoogi, mis toimub loomulikus (eesti) keeles ning inimestevahelise suhtluse normide ja reeglite järgi (Koit, Õim 2003).

Siiski pole kõik uurijad üksmeelel selles, kas arvuti peaks inimesega suhtlema täpselt nii nagu inimene. On püstitatud nn arvutikõne hüpotees (Zoeppritz 1985), mis väidab, et inimesed ei oota arvutilt, et ta suhtleks nendega nagu inimene, vaid kohanevad arvuti piiratusega. Ometi on selge, et mida kaugemale tehnoloogia areneb, seda vähemaks jääb selliseid piiranguid. Nii või teisiti, dialoogsüsteemi kavandamisel tuleb uurida nii inimestevahelist kui ka inimese ja arvuti vahelist suhtlust, et kinnitada või ümber lükata arvutikõne hüpoteesi. Kuni dialoogsüsteemi pole veel loodud, ei saa muidugi koguda inimese ja arvuti vahelisi dialooge. Siis kasutatakse nn võlur Ozi meetodit (Dahlbäck jt 1993): inimestel palutakse justkui testida programmi, mis suhtleb nendega loomulikus keeles, kuid tegelikult etendab arvuti rolli arvutivõrgu kaudu teine inimene ("võlur Oz"). Teine võimalus on olemasolevate inimestevaheliste dialoogide nn destilleerimine, eesmärgiga muuta neid “arvutilaadseteks” (Jönsson, Dahlbäck 2000). 
Kogutud dialoogid koondatakse korpustesse ning dialoogikorpusi märgendatakse mitmel tasemel: fonoloogilisel, morfoloogilisel, süntaktilisel, dialoogiaktide tasemel jne.

\subsection{Eesti dialoogikorpus}

Eesti dialoogikorpuse (EDiK) loomist alustati Tartu Ülikoolis 2001. aastal (Koit 2003). Korpus sisaldab praegu kolme liiki dialooge: ${ }^{24}$

1. inimestevahelised dialoogid Tartu Ülikooli suulise eesti keele korpusest. ${ }^{25}$ Seisuga september 2006 sisaldab korpus 884 litereeritud telefonikõnet ja silmast-silma vestlust, kokku u 155 ooo tekstisõna;

2. võlur Ozi meetodil kogutud kirjalikud dialoogid, kus arvuti rolli on etendanud inimene, 21 reisiinfodialoogi (2500 sõna);

3. lihtsate veebis kasutatavate dialoogsüsteemidega ${ }^{26}$ Reisiagent ja Teatriagent peetud dialoogid (programmide autor Margus Treumuth).

Osa suulisi dialooge on märgendatud morfoloogiliselt ja süntaktiliselt. Selleks on kasutatud eesti kirjakeele morfoloogilist analüsaatorit ESTMORF (Kaalep 1998) ja eesti keele kitsenduste grammatika süntaktilist analüsaatorit (Müürisep 2000), mida on kohandatud suulisele keelele. Kõigis dialoogides (v.a Reisi- ja Teatriagendiga peetud dialoogid) on märgendatud dialoogiaktid. Selleks on Tartu Ülikoolis välja töötatud vestlusanalüüsil põhinev dialoogiaktide tüpoloogia, mis sisaldab üle 120 akti (Hennoste, Rääbis 2004). Iga dialoogi märgendavad teineteisest sõltumatult kaks inimest ja kolmas ühtlustab. Aktid jagunevad naaberpaare moodustavateks ja üksikaktideks. Naaberpaaril on esi- ja järelliige, mida väljendatakse aktide nimedes. Aktide nimed koosnevad kahest osast: akronüüm, mis näitab akti paiknemist tüpoloogias ja naaberpaariakti puhul lisaks, kas on tegu esi- või järelliikmega (nt RIE on rituaalide rühma esiliige, IL on üksikaktide rühm infolisa), ja akti pärisnimi (nt KUTSUNG, TÄPSUSTAMINE). Need kolm dialoogitüüpi on esitatud näidetes (8-10).

(8) EDiK: kahe inimese telefonidialoog. $\mathrm{H}$ - helistaja (klient), V - vastaja (ametnik). Kasutatud on vestlusanalüüsi transkriptsiooni (Hennoste, Rääbis 2004)

((kutsung)) | RIE: KUTSUNG |

V: bussi'info=kuuleb $=\quad$ | RIJ: KUTSUNGI VASTUVÕTMINE $\mid$ | RIE: ESITLUS |

tere RIE: TERVITUS |

H: 'hh tere. | RIJ: VASTUTERVITUS |

.h mul on=nüd selline ' küsimus. |YA: EELTEADE |

(.) $\mathrm{mt}$ e < ' mis (o.5) e 'kell 'läheb (.) selline 'buss mis jõuaks > (.) e 'Soome mineva 'laeva 'peale. | KYE: AVATUD |

'Soome minev 'laev läheb 'Tallinast (.) kell=' kaheksa. | YA: INFOLISA: TÄPSUSTAMINE |

(0.5)

'kas 'lähevad bussid ka: 'sadamasse. | KYE: SULETUD KAS |

V: ei, | KYJ: EI |

\footnotetext{
24 http://math.ut.ee/ koit/Dialoog/EDiC.html (8.09.2006)

25 http://www.cl.ut.ee/suuline/ (8.09.2006)

${ }^{26} \mathrm{http}: / /$ math.ut.ee/ treumuth (8.12.2006)
} 
'sadamasse läheb ainut 'üks' ainuke 'buss, | KYJ: INFO ANDMINE | see sõidab 'Tartust väljust välja 'kaksteist neligend='viis. | IL: TÄPSUSTAMINE |

Korpusesse kogutud dialoogide analüüs võimaldab vastata mitmesugustele küsimustele selle kohta, missugune peaks olema suhtlus arvutiga võrreldes inimestevahelise suhtlusega, sh missugune peaks olema arvuti sõnavara ja grammatika, kuidas lahendada mitmesusi, kuidas kasutada konteksti jms (vt nt Gerassimenko, Valdisoo 2006).

(9) EDiK: dialoog võlur Oziga (sisend klaviatuurilt, väljund ekraanile)

Infoklient: mis kell väljub buss Tartust Võrru, et ma oleksin Võrus juba kell 17.00? | KYE: AVATUD |

Infoklient: mind huvitab lähim buss | IL: TÄPSUSTAMINE |

VOZ: Oodake, palun! | DIE: PALVE OODATA |

VOZ: Buss väljub kell 14.15 ja saabub Võrru kell 15.50

| KYJ: INFO ANDMINE |

Infoklient: Kas see buss sõidab läbi Põlva? | KYE: SULETUD KAS |

VOZ: Jah. | KYJ: JAH |

Infoklient: Mis kell ta peatub Põlvas? | KYE: AVATUD |

VOZ: Buss peatub Põlvas kell 15.15 | KYJ: INFO ANDMINE

VOZ: Kas saan Teile veel kasulik olla? | KYE: SULETUD KAS | | TVE: TEEMAALGATUSE PAKKUMINE |

(10) EDiK: dialoog arvutiga (Reisiagent; sisend klaviatuurilt, väljund ekraanile ja sünteeskõnes). $\mathrm{K}$ - kasutaja, A - arvuti

K: tere!

A: Tere. Kuhu soovite lennata?

$\mathrm{K}$ : soovin lennata itaaliasse

A: Itaalia puudub lennuandmebaasist.

K: Siis tahan lennata prantsusmaale

A: Pariisi saab lennata teisipäeval kell o8:00.

K: tahaksin lennata hoopis 6. aprillil

A: Neljapäeval saab Pariisi lennata kell o8:0o.

$\mathrm{K}$ : kust ma piletit osta saan?

A: Pileti saate Estraveli kassast.

Soovides luua sellist dialoogsüsteemi, mis täidaks infoametniku rolli, peame eeskujuna silmas ideaalset ametnikku, kes on viisakas, koostöövalmis, korrektse keelekasutusega jms. Näide (11) on inimestevahelise suulise dialoogi destilleerimise kohta, kus on muudetud ametniku (V) keelekasutust ja on lisatud kliendi (H) küsimus. Destilleeritud dialoogis võiks ametniku rolli täita arvuti.

(11) Dialoog (a) enne ja (b) pärast destilleerimist

(a)

$\mathrm{H}$ :

(0.5)

'kas 'lähevad bussid ka: 'sadamasse.

$\mathrm{V}$ : ei,

'sadamasse läheb 'üks' ainuke 'buss, 
see sõidab 'Tartust väljust välja 'kaksteist neligend='viis.

(b)

$\mathrm{H}$ :

(0.5)

'kas 'lähevad bussid ka: 'sadamasse.

V: ei,

'sadamasse läheb ainult 'üks 'buss,

$\mathrm{H}$ : millal see väljub?

V: see sõidab 'Tartust välja 'kaksteist nelikümmend='viis.

\subsection{Loomuliku keele töötlus dialoogsüsteemis}

Dialoogsüsteem täidab tsükliliselt kolme järjestikust protsessi: 1. kasutaja lausungi (nt küsimuse) analüüs, 2. probleemilahendus (leidmaks vastust küsimusele), 3. oma lausungi süntees. Analüüsi võib omakorda jagada etappideks: kõne teisendamine tekstiks (kõnetuvastus) ja seejärel teksti morfoloogiline, süntaktiline ja semantiline analüüs. Samasugusteks etappideks (vastupidises järjekorras) saab jaotada ka vastuse sünteesi. Probleemilahendus on ainus protsess, mis ei sõltu keelest ja kasutab teatava formalismi abil esitatud maailmateadmust, andmebaase, mitmesuguseid universaalseid ja spetsiifilisi probleemilahendusmeetodeid.

Eesti keele automaattöötluseks on valminud juba mitmesugust tarkvara. Sellest annab ülevaate tabel 2.

Morfoloogiatarkvara on erinevatel teoreetilistel alustel loodud nii Tartu Ülikoolis (koos firmaga Filosoft) kui ka Eesti Keele Instituudis (Kaalep 1998, Viks 2000). Eesti keele kitsenduste grammatika baasil on koostatud reeglipõhine süntaktiline analüsaator (Müürisep 2000) ja morfoloogiline ühestaja (Puolakainen 2001). Firmas Filosoft on lisaks loodud teine morfoloogiline ühestaja, mis põhineb Markovi peitmudelil. Eesti keele sõnatähenduste ühestaja (Kaljurand 2004) kasutab mitmetähendusliku sõna vaadeldavasse konteksti sobiva tähenduse väljavalimiseks eesti WordNetti $^{27}$ ning kitsenduste grammatika süntaksianalüsaatorit. Dialoogiaktide klassifitseerimisel rakendatakse tehisnärvivõrke ja otsustuspuid (Fišel, Kikas 2006), kusjuures klassifitseerimise aluseks on Eesti dialoogiaktide tüpoloogia ja klassifitseerimisprogramme treenitakse Eesti dialoogikorpusel. Tekst-kõnesüntesaatoris rakendatakse kompilatiivset meetodit, kasutades difoonide andmebaasi (Mihkla, Meister 2002). Kõnetuvastaja on statistikapõhine (Alumäe 2003).

Tabel 2. Eesti keele tarkvara

\begin{tabular}{|l|l|l|}
\hline Keeletöötluse tase & Tarkvara & Asutus \\
\hline Morfoloogia & Morfoloogiline analüsaator ja süntesaator ${ }^{28,29}$ & TÜ, Filosoft, EKI \\
\hline Süntaks & $\begin{array}{l}\text { Kitsenduste grammatika süntaktiline analüsaator, } \\
\text { morfoloogiline ühestaja }\end{array}$ & $\begin{array}{l}\text { TÜ } \\
\text { TÜ, Filosoft }\end{array}$ \\
\hline Semantika ja pragmaatika & $\begin{array}{l}\text { Sõnatähenduste ühestaja, } \\
\text { dialoogiaktide klassifitseerija }\end{array}$ & TÜ \\
\hline Kõnetöötlus & Tekst-kõne süntesaator, ${ }^{28}$ kõnetuvastaja & TTÜ, EKI \\
\hline
\end{tabular}

\footnotetext{
${ }^{27}$ http://www.cl.ut.ee/ressursid/teksaurus (8.09.2006)

28 http://www.filosoft.ee/html_morf_et/ (8.09.2006)

${ }^{29} \mathrm{http} / / /$ www.eki.ee/tarkvara/ (8.09.2006)

${ }^{30} \mathrm{http}: / /$ www.cs.ut.ee/ kaili/parser/demo/ (8.09.2006)

31 http://math.ut.ee/ kaarel/NLP/ (8.09.2006)
} 
Eespool nimetatud dialoogsüsteemid Reisiagent ja Teatriagent kujutavad endast katseid ühendada olemasolevat eesti keele tarkvara lihtsate küsimus-vastusdialoogide läbiviimiseks. Mõlemal juhul on tegu kitsalt piiritletud ülesandega: Reisiagent vastab kasutaja küsimustele lennukite väljumisaegade kohta Tallinna lennujaamast ning Teatriagent annab infot Eesti teatrite mängukava osas. Mõlema süsteemiga suhtlemine toimub sel viisil, et kasutaja sisestab veebibrauseris päringuaknasse oma küsimuse ja näeb ekraanil vastust ning soovi korral kuuleb sedasama sünteeskõnes. Teatriagendile on lisatud ka kõnetuvastusmoodul (mitte veel veebiversioonis), nii et kasutaja saab oma küsimuse esitada hoopis suuliselt. Kirjaliku eesti keele töötlemise tarkvarast on mõlemas süsteemis rakendatud üksnes morfoloogilist analüüsi ja sünteesi. See on siin otstarbekohane: piiratud ainevaldkonna korral ei ole vaja läbi teha analüüsi täistsüklit, mõlemad süsteemid otsivad kasutaja küsimusest ainult sobivaid märksõnu (nt kuupäeva, teatri või linna nime jms) ja vastuse sünteesimise asemel saab kasutada valmis vastuste šabloone, milles üksnes täidetakse tühje kohti (Treumuth 2006).

\subsection{Eestikeelsed kasutajaliidesed}

Paljud arvutiprogrammid peavad suuremal või vähemal määral suhtlema kasutajaga, kas või ainult algandmete sisestamiseks ja tulemuste väljastamiseks. Näiteks programm, mis arvutab kolmnurga pindala kolme külje järgi, teatab kasutajale:

$$
\begin{aligned}
& \text { Sisestage kolmnurga küljepikkused } \\
& \mathrm{a}= \\
& \mathrm{b}= \\
& \mathrm{c}=
\end{aligned}
$$

ja väljastab tulemuse

Kolmnurga pindala $\mathrm{S}=\ldots$

Selline kasutajaliides ei nõua küll loomuliku keele analüüsi ega sünteesi, kuid ometi peab programmeerija suutma ette näha kasutaja käitumist, võimalikke veaolukordi ja tagama, et kõik teated, mida arvuti väljastab, oleksid informatiivsed, keeleliselt korrektsed ja üheselt mõistetavad. Kui eelmises näites sisestab kasutaja negatiivse arvu, siis võiks järgneda veateade

Küljepikkus peab olema positiivne, sisestage uuesti.

Dialoogis (12) on toodud näide keelemängu Alias eestikeelsest kasutajaliidesest. ${ }^{32}$ Programm võtab sõnaseletused eesti WordNetist.

(12) Dialoog programmiga Alias. Kasutaja vastused algavad märgiga > Alustame mängu

Niisiis uus sõna

isik, kellel on loomuniguline ${ }^{33}$ ja kujutuslik tegevus

$>$ kunstnik

Näitelause:

Mulle meeldis väga selle kunstniku näitus

$>$ artist

32 http://www.cl.ut.ee/lahe/ (5.05.2006)

33 Siin on ilmselt tegu veaga andmebaasis (peaks olema: loominguline). 
kunstnik

$>$ maalija

on teatud liiki looja

$>$ maalikunstnik

Selle sõna teatud liigid on esineja, maalija, disainer, komponist

$>$ interpreet

Selle sõna üks liik on dirigent

$>$ loomeinimene

Rohkem seletusi mul anda pole. Võid veel pakkuda

$>$ kunstiinimene

kunstiinimene on õige :)

\section{Suhtlus arvutiga tulevikus}

Tuntud arvutiteadlane, Sheffieldi ülikooli professor Yorick Wilks näeb dialoogsüsteemide tulevikku robot-kaaslastes, mida ta nimetab kompanjonideks (Wilks 2006). Kompanjon on konversatsiooniagent, juurdepääsuga Internetile. Ta on isikustatud oma omaniku suhtes: teab tema vajadusi, eelistusi, harjumusi ning õpib omaniku kohta süstemaatiliselt juurde. Ta võib olla näiteks mänguasja- või lemmikloomakujuline, mida saab ranitsas kaasas kanda. Eraldi väärivad märkimist seeniorkompanjonid vanuritele ja juuniorkompanjonid lastele. Seeniorkompanjon võib oma omanikule meelde tuletada huvitava telesaate algust, lülitades sisse televiisori, ravimi võtmise aega, vanuriga lihtsalt suhelda, vajaduse korral talle abi kutsuda jms. Juuniorkompanjon hoiatab kooliteed alustavat last ohtude eest liikluses, aitab koolitükke ette valmistada, otsides infot Internetist, ajakavast kinni pidada jne.

Kompanjonid on uus agentide liik vastukaaluks passiivsele veebile: veeb peab muutuma personaalsemaks, et olla hoomatav ka kiirelt kasvades. Semantiline veeb on esimene samm veebi struktureerimiseks, aga praegused veebiagendid on siiski veel abstraktsed ja ajutised. Personaalsed agendid peavad olema autonoomsed, püsivad ja usaldusväärsed ka selliste elanikkonna kihtide jaoks, kes praegu on veebist eemal.

Tulles lõpuks tagasi algul mainitud Turingi testi juurde, võib viidata Ameerika arvutiteadlase ja visionääri Raymond Kurzweili sõnavõtule ${ }^{34}$ 2001. a, kus ta rõhutas, et Turingi test on märkimisväärne sellepoolest, et näitab, kuidas keel peegeldab inimmõtlemist. Praegu on olemas palju arvutiprogramme, mis suudavad kitsa ainevaldkonna probleeme lahendada niisama hästi kui inimene: malemäng, meditsiiniline diagnoosimine, finantsotsuste vastuvõtmine jpm. Seega võib väita, et arvuti suudab nendes valdkondades täita Turingi testi. Et arvuti läbiks Turingi testi täies mahus, s.t et ta suudaks suhelda nagu inimene, peaks tal olema inimese tasemel mõtlemisvõime.

R. Kurzweili arvates saab see võimalikuks aastal 2029. 


\section{Kokkuvõte}

Maailmas on olemas tuhandeid VoiceXML-põhiseid kommertssüsteeme, mis suhtlevad inimestega kõne abil ja töötlevad miljoneid telefonikõnesid päevas. Pakutavate teenuste skaala on lai: infotelefon, hädaabi, lennu reserveerimine, postisaadetiste jälgimine, telefonikõne suunamine nime järgi, kinnisvarainfo jne.

Suund on võetud hübriidsüsteemidele, milles kombineeritakse reeglipõhiseid ja korpusepõhiseid meetodeid, ning multimodaalsele suhtlusele, kus lisaks kõnele kasutatakse miimikat ja žeste.

On loodud mitmeid roboteid, mis muuhulgas suudavad inimesega loomulikus keeles suhelda. Tulevikku nähakse sellistes robotites-kompanjonides, mis on võimelised õppima, kohanema omaniku vajadustega ja teda abistama.

Eesti keeles suhtleva arvuti arendamiseks on Tartu Ülikoolis loodud eesti dialoogikorpus, samuti on olemas mitmesugust eesti keele automaattöötluse tarkvara. Osaliselt on seda rakendatud kahes lihtsas küsimus-vastussüsteemis Reisiagent ja Teatriagent, mida saab veebis kasutada. Eesmärk on luua selline dialoogsüsteem, mis täidaks infoametniku rolli ja suudaks kasutaja dialoogiakte automaatselt tuvastada ning neile reageerida nii nagu inimene.

\section{Kirjandus}

Alumäe, Tanel 2003. Eestikeelse kõne tuvastus: prototüübi loomine. - M. Langemets, H. Sahkai, M.-M. Sepper (toim.). Toimiv keel I. Töid rakenduslingvistika alalt. Eesti Keele Instituudi toimetised 12. Tallinn: Eesti Keele Sihtasutus, 34-49.

Brown, Peter F.; Cocke, John; Della Pietra, Stephen A.; Della Pietra, Vincent J.; Jelinek, Fredrik; Lafferty, John D.; Mercer, Robert L.; Roossin, Paul S. 1990. A statistical approach to machine translation. - Computational Linguistics 16 (2), 79-85.

Dahlbäck, Nils; Jönsson, Arne; Ahrenberg, Lars 1993. Wizard of Oz studies. Why and how. - Knowledge-Based Systems 6 (4), 258-266.

Fišel, Mark; Kikas, Taavet 2006. Dialoogiaktide automaatne tuvastamine. - M. Koit, R. Pajusalu, H. Õim (toim.). Keel ja arvuti. Tartu Ülikooli üldkeeleteaduse õppetooli toimetised 6. Tartu: Tartu Ülikooli Kirjastus, 233-245.

Gerassimenko, Olga; Valdisoo, Maret 2006. Loomulik infodialoog ja infodialoogi simulatsioon: infoandja strateegiad. - M. Koit, R. Pajusalu, H. Õim (toim.). Keel ja arvuti. Tartu Ülikooli üldkeeleteaduse õppetooli toimetised 6. Tartu: Tartu Ülikooli Kirjastus, 196-209.

Hennoste, Tiit; Rääbis, Andriela 2004. Dialoogiaktid eesti infodialoogides: tüpoloogia ja analüüs. Tartu: Tartu Ülikooli Kirjastus.

Jönsson, Arne; Dahlbäck, Nils 200o. Distilling dialogues. A method using natural dialogue corpora for dialogue systems development. - Proceedings of 6th Applied Natural Language Processing Conference. Seattle, 44-51.

Kaalep, Heiki-Jaan 1998. Tekstikorpuse abil loodud eesti keele morfoloogiaanalüsaator. - Keel ja Kirjandus 1, 22-29.

Kaljurand, Kaarel 2004. Word Sense Disambiguation of Estonian with syntactic dependency relations and WordNet. - Proceedings of ESSLLI-2004. Nancy, France, 128-137.

Koit, Mare 2003. Märgendatud dialoogikorpus kui keeleressurss. - M. Langemets, H. Sahkai, M.-M. Sepper (toim.). Toimiv keel I. Töid rakenduslingvistika alalt. Eesti Keele Instituudi toimetised 12. Tallinn: Eesti Keele Sihtasutus, 119-136.

Koit, Mare; Õim, Haldur 2003. Eestikeelse dialoogi modelleerimine. - Keel ja Kirjandus $10,721-735$. 
McTear, Michael F. 2004. Spoken Dialogue Technology. Toward the Conversational User Interface. London: Springer Verlag.

Mihkla, Meelis; Meister, Einar 2002. Eesti keele tekst-kõne-süntees. - Keel ja Kirjandus 2, 88-97; 3, 173-182.

Minker, Wolfgang; Bühler, Dirk; Dybkjær, Laila (Eds.) 2005. Spoken Multimodal HumanComputer Dialogue in Mobile Environments. Text, Speech and Language Technology. Vol. 28. London: Springer Verlag.

Müürisep, Kaili 200o. Eesti keele arvutigrammatika: süntaks. Dissertationes Mathematicae Universitatis Tartuensis 22. Tartu: Tartu Ülikooli Kirjastus.

Puolakainen, Tiina 2001. Eesti keele arvutigrammatika: morfoloogiline ühestamine. Dissertationes Mathematicae Universitatis Tartuensis 28. Tartu: Tartu Ülikooli Kirjastus.

Turing, Alan M. 1950. Computing machinery and intelligence. - Mind. New Series 59 (236), 433-460.

Turing, Alan M. 2005. Arvutusmasinad ja intellekt. - Elo Tuur (tõlk.). Akadeemia 12, 2572-2606.

Treumuth, Margus 2006. A Natural Language Interface to a Theater Information Database. Proceedings of SPECOM. St.-Petersburg, 179-181.

Viks, Ülle 200o. Eesti keele avatud morfoloogiamudel. - T. Hennoste (toim.). Arvutuslingvistikalt inimesele. Tartu Ülikooli üldkeeleteaduse õppetooli toimetised 1. Tartu: Tartu Ülikooli Kirjastus, 9-36.

Zoeppritz, Magdalena 1985. Computer Talk? (Technical Report 85.05) - Heidelberg: IBM, WZH.

Weizenbaum, Joseph 1966. ELIZA - a Computer Program for the Study of Natural Language Communication between Man and Machine. - Communications of the ACM 9 (1), 36-35. http://www.acm.org/cacm (4.05.2006).

Wilks, Yorick 2006. Artificial Companions as a new kind of interface to the future Internet. - Oxford Internet Institute. Research Report No. 13. http://www.oii.ox.ac. $\mathrm{uk} /$ research/publications.cfm (8.12.2006).

Williams, Jason D.; Young, Steve 2006. Partially Observable Markov Decision Processes for Spoken Dialog Systems. - http://svr-www.eng.cam.ac.uk/ sjy/papers/wiyoo6.pdf (8.09.2006). Computer Speech and Language (accepted for publication).

Mare Koit on Tartu Ülikooli keeletehnoloogia professor, uurimisvaldkondadeks on keeletehnoloogia, tehisintellekt ning dialoogi modelleerimine arvutil.

mare.koit@ut.ee 


\section{INTERACTION WITH THE COMPUTER}

\section{Mare Koit}

Univesrity of Tartu

The paper investigates some problems which have to be solved in order to enable interaction with the computer in a natural language, incl. Estonian. Examples of interaction with the computer are given, starting with the Turing's idea of an intelligent computer (1950) and finishing with contemporary dialogue systems and robots that have natural user interfaces. Academic and engineering approaches to the building of dialogue systems are introduced as well as two paradigms of dialogue processing - rationalism and empiricism. An overview is given of work hitherto done on a dialogue system which interacts with a user in Estonian, incl. the Estonian dialogue corpus of the University of Tartu and software for Estonian language processing. Finally, visions of some well known scientists about the future computer as an interactive partner are intermediated.

Keywords: Turing test, computer speech hypothesis, dialogue system, robot, dialogue corpus, Estonian 